\title{
Liderazgo en organizaciones venezolanas
}

\author{
Loaiza, Carmen Teresa* \\ Pirela, Ligia**
}

\section{Resumen}

El presente artículo tiene como objetivo analizar el liderazgo en organizaciones venezolanas; se presentan conceptos de líder y liderazgo y se revisan teorías tradicionales y enfoques contemporáneos. Finalmente se indaga sobre estilos de liderazgo presentes en organizaciones venezolanas insertas en los sectores: educativo, pequeña y mediana industria y empresarial. La investigación es teórico-documental, el diseño es bibliográfico y la técnica es documental. Se consultan autores como Bennis y Nanus (1985), Bass y Avolio (1994), Echeverría (2006), Echeverría (2011), Lussier y Achúa (2005) y Goleman et al (2005), Robbins (2009), Bittel y Newstron (1993), entre otros para caracterizar los aspectos más representativos sobre la variable en estudio, así como investigaciones de organizaciones venezolanas. Entre los hallazgos se encuentra una tendencia a requerir líderes más fortalecidos y orientados a la competitividad, con visión transformadora y promotores de confianza, de participación, de conocimiento y de actitud favorable, traducida en optimismo. Líderes innovadores y que otorguen empowerment a su gente, empáticos al definir sus estrategias y flexibles en la ejecución de las mismas. El líder venezolano como un privilegiado en creatividad y potencialidad de innovación así como emprendedor.

Palabras clave: Liderazgo, líder, organizaciones, teorías tradicionales de liderazgo, enfoques de liderazgo.

Recibido: 10-11-13. Aceptado: 05-02-15

Magíster en Gerencia de Empresas, Universidad del Zulia (LUZ), Licenciada en Administración de Empresas de la Universidad Rafael Urdaneta (URU). Profesor Asociado. Escuela de Administración y Contaduría Pública. Facultad de Ciencias Económicas y Sociales. Universidad del Zulia. Departamento de Ciencias Administrativas. E-mail: carmen.loaiza@logros. com

** Doctora en Ciencias Humanas (LUZ). Magíster en Gerencia de Empresas (LUZ), Psicóloga (URU). Profesora Titular. Jefa del Departamento de Investigación. Escuela de Comunicación Social. Facultad de Humanidades y Educación, Universidad del Zulia. E-mail: ligiapirela@hotmail. com 


\title{
Leadership in Venezuelan Organizations
}

\begin{abstract}
The objective of this article is to analyze leadership in Venezuelan organizations. Concepts regarding the leader and leadership are presented and traditional theories and contemporary approaches are reviewed. Finally, an investigation is made regarding styles of leadership existing in Venezuelan organizations located in the educational and entrepreneurial sectors and in small and medium industries. The research is theoretical-documentary, the design is bibliographic and the technique is documentary. Authors such as Bennis and Nanus (1985), Bass and Avolio (1994), Echeverría (2006), Echeverría (2011), Lussier and Achúa (2005), Goleman et al (2005), Robbins (2009) and Bittel and Newstron (1993), were consulted, among others, to characterize the most representative aspects regarding the variable under study, as well as research regarding Venezuelan organizations. Findings indicated that a tendency exists to require leaders that are strengthened for and oriented toward competitiveness, who have a transforming vision, who promote confidence, participation, knowledge and a favorable attitude, translated into optimism; innovative leaders and those who bestow empowerment on their people, who are empathetic when defining their strategies and flexible in executing the same. The Venezuelan leader is seen as a person privileged in creativity and potential for innovation as well as enterprising.
\end{abstract}

Key words: Leadership, leader, organizations, traditional leadership theories, leadership approaches.

\section{Introducción}

En la actualidad, las organizaciones periódicamente se han visto en la necesidad de replantear sus estilos de liderazgo y sus prácticas gerenciales, bajo el claro conocimiento de los cambios que se han originado en el entorno desde todos los espacios: económicos, sociales, políticos entre otros, y donde en especial, se ha visto impactado el talento humano que habita dentro de ellas.

El líder en las organizaciones es sistemáticamente estudiado, pues su gestión incide de manera favorable o no en los resultados. Su impacto en los seguidores puede derivar en clima laboral saludable o improductivo, su forma de interactuar con el equipo de trabajo determina la sinergia o el enfoque único donde se limita la participación, pues justamente el liderazgo in- fluye en los seguidores, y estos conforman el volumen más numeroso en las organizaciones y los sistemas.

Es por ello pertinente continuar estudiando el liderazgo, pues es una competencia medular en la gestión organizacional, y de ello depende en gran medida el alcance de la visión, objetivos, estrategias aplicadas y la armonía con que todos los elementos se conjugan.

Las nuevas formas de liderazgo que aspiran las organizaciones evidencian un desplazamiento desde viejos esquemas autocráticos, capataces, con enfoque único y orientado a los resultados, hacia estilos más democráticos, participativos, donde no solo el resultado sino el proceso, las prácticas y la consideración hacia el talento humano, son determinantes para el éxito de la gestión. Hay orientación ahora al estudio de las competen- 
cias no solo profesionales, sino también a las que abordan al ser humano como integral, dotado de valores, motivaciones, intereses, emociones; un ser que siente, que piensa y que anida dentro de sí un mundo único e irrepetible.

Es así como el liderazgo se define comúnmente como la habilidad para conducir a un grupo hacia el logro del objetivo, que desarrolla el potencial, gana la confianza y lealtad, con lo cual obtiene eficiencia, eficacia y productividad.

Es menester continuar fortaleciendo este rol, que no solo se alimenta de conocimientos y técnicas, de habilidades y destrezas, sino también de un componente importante de pasión, energía, inspiración y emocionalidad resonante, tal como refiere la teoría de liderazgo resonante o el modelo de liderazgo coach. Se requiere así un liderazgo basado en capacidad de transformación y reconocimiento de las potencialidades de los trabajadores.

En tal sentido y desde la necesidad de continuar ofreciendo a la gerencia organizacional la revisión de prácticas de liderazgo, es pertinente ofrecer un análisis del concepto de liderazgo y líder y como éste se ha desarrollado en las organizaciones venezolanas. Abordar teorías recientes y contemporáneas que dan respuesta a las necesidades de las organizaciones de hoy, revisar algunos estudios que se han efectuado al respecto, para orientar prácticas más eficientes que satisfagan no solo los intereses organizacionales, sino los de todos en conjunto como parte de una visión compartida que trasciende hacia la sociedad.

Al indagar acerca del liderazgo, Lussier y Achúa (2005), refieren que es el proceso de influencia entre líderes y seguidores para lograr objetivos organizacionales por medio del cambio. Pudiéndose definir en principio como la capacidad y el proceso mediante el cual un individuo influye sobre la conducta de los demás, con el fin de lograr los objetivos propuestos. En esta definición, se visualizan diferentes elementos del fenómeno: líder, seguidores y objetivo.

En este sentido, la influencia es determinante y ocurre cuando se producen cambios en las actitudes, percepciones y comportamientos de otros, y puede darse a través de procesos de modelaje, consejo o sugerencia, persuasión y coerción; puede tener como resultado, el compromiso, cuando se dan cambios en las percepciones y las actitudes, el cumplimiento mínimo cuando se enfatiza solo en el comportamiento, o la resistencia a realizar lo solicitado. Al respecto, Lussier y Achua (2005), consideran que influir es el proceso en el que el líder comunica sus ideas, los seguidores las aceptan y se sienten motivados para respaldarlas y efectuar el cambio. La influencia es la parte medular del liderazgo, y tiene que ver con la relación que se establece entre líderes y seguidores, donde los primeros se ganan la voluntad y el entusiasmo de los segundos, quienes están dispuestos a que influyan sobre ellos.

A su vez, el liderazgo es una forma de poder, en una relación entre personas. No todas las influencias humanas son necesariamente coercitivas o explotadoras, ni todas las transacciones entre las personas son mecánicas, impersonales y efímeras. La influencia más poderosa consiste en una relación humana profunda en las que una o más personas se comprometen en- 
tre sí. Esta descansa en una comprensión más realista y sofisticada de poder y del ejercicio de la persuasión mutua, intercambio, elevación y transformación.

En tal sentido, el objetivo de ésta investigación se centra en analizar el liderazgo en organizaciones venezolanas. Esto como una inquietud de continuar revelando mejores prácticas en el estilo de liderazgo en el país, dado el rol que el líder ejerce dentro del contexto organizacional y su impacto en los resultados. Se presentan en principio los conceptos de líder y liderazgo desde diferentes perspectivas y se comparan las teorías tradicionales y los enfoques contemporáneos. Posteriormente se esbozan los resultados en algunos sectores estudiados desde el liderazgo. La investigación es teórico-documental, el diseño es bibliográfico y la técnica es documental.

\section{Principales teorías tradicionales del liderazgo}

Si se profundiza en los conceptos que los expertos (Robbins, 2009; Bittel y Newstron, 1993; Bennis y Nanus, 1985; De Pree, 1993; Lussier y Achua, 2005) han definido sobre liderazgo se entiende la complejidad de dicho fenómeno. Hay en éste tres aspectos a considerar: el líder, el seguidor y la situación. Robbins (2009) y Bittel y Newstron (1993) lo asocian con los rasgos de personalidad, físicos o comportamientos, mientras que otros, en cómo la situación afecta el proceso. Esto conduce a pensar que no existe una única definición, y que la variedad contribuye a observar la cantidad de factores y perspectivas que inciden en éste concepto.
Otro aspecto de interés es el planteado por Bennis y Nanus (1985), quienes plantean que, para que el líder ejerza influencia deben estar presentes tres conceptos principales: compromiso, complejidad y credibilidad. Los líderes deben saber comunicar una visión, darle significado y propiciar el empuje para alcanzarla. Es decir, que el liderazgo eficaz mueve a las organizaciones de sus estados actuales a futuros, crea visiones de oportunidades potenciales para las organizaciones, inculca a los empleados el compromiso para el cambio, y en las organizaciones nuevas culturas y estrategias que movilizan y concentra la energía y los recursos.

Los líderes entonces se revelan cuando las organizaciones enfrentan problemas nuevos y complejidades que no pueden resolverse sin una guía planificada, asumen responsabilidades para reformar las prácticas organizacionales, las adaptan a los cambios del entorno y superan la resistencia al cambio, creando visiones de futuro que evocan la confianza y el dominio de nuevas prácticas organizacionales.

Desde otra perspectiva, De Pree (1993), plantea que los líderes deben dominar dos conceptos poco comunes: la voz, que es la expresión de las creencias personales; y el contacto, que demuestra la aptitud y la resolución de un verdadero líder, lo cual exige un gran esfuerzo y es un gran privilegio. Enumera entre los principales atributos que un líder debe poseer: integridad, vulnerabilidad, discernimiento, conocimiento del espíritu humano, energía en las relaciones, sentido de humor, intelecto y curiosidad, previsibilidad, amplitud, comodidad con la ambigüedad y presencia. 
Por su parte, Lussier y Achua (2005), plantean cinco grandes dimensiones de la personalidad del líder: emocionalidad, empatía, ajuste, escrupulosidad y apertura a la experiencia. La emocionalidad según ellos, se refiere a la extroversión como una característica de personas dominantes que se quieren hacer cargo de la situación, dirigir, competir e influir.

La empatía está asociada a la armonía interpersonal, a la calidez en las relaciones, al trato fácil, a la compasión y sociabilidad. El ajuste comprende rasgos de estabilidad emocional, al autocontrol, seguridad y ser positivo. La escrupulosidad contiene los aspectos relacionados con el logro, ser responsable y digno de confianza, asociado a la credibilidad, la accesibilidad y la organización. La gente con este rasgo se caracteriza por estar dispuesta a trabajar arduamente y conceder tiempo y esfuerzo adicionales para cumplir con los objetivos y lograr buenos resultados. La apertura a la experiencia, se manifiesta en disposición a cambiar y probar cosas nuevas.

En síntesis, las características que el líder debe poseerse son: motivación al logro, ambición, energía, tenacidad, iniciativa, poder, honestidad, integridad, autoconfianza, habilidades cognitivas, conocimiento de la situación, carisma, creatividad, flexibilidad, visión, patrones de comportamiento e interacción, adaptables a la situación y a las necesidades de los seguidores. El líder inspira y arrastra a los seguidores. Sin embargo, no hay una lista de rasgos o características aceptadas por todos los estudiosos y no todos los líderes eficaces poseen todos estos atributos.

Es por ello, que al realizar un recorrido por las teorías tradicionales del lideraz- go, Robbins (2009) y Bittel y Newstron (1993), fomentan la comprensión del ejercicio del liderazgo en el presente trabajo.

La teoría de las características, también denominada de los rasgos, indica que las personas poseen aspectos individuales que las caracterizan, y esas particularidades diferencian a quiénes pueden considerarse líderes de aquellas que no lo son.

Según Robbins (2009), una de las más importantes conclusiones de esta teoría, es que las características definen el liderazgo y son buenas como indicadores para observar el líder que destaca y su apariencia, no obstante no es una teoría que pueda ser muy útil para determinar la eficiencia o no de un líder.

Aun cuando los intentos por identificar características, rasgos o cualidades han orientado a estudiosos en la materia y aportado a la gerencia moderna indicadores importantes para sus programas de desarrollo, evaluación de competencias, entre otros procesos, no son suficientes para explicar el liderazgo, ya que, cuando solo se observan características se olvidan las interacciones, los actores involucrados en el proceso y los factores situacionales.

Ahora bien, en cuanto a la teoría basada en el comportamiento, es la primera teoría orientada a profundizar en éste ámbito del ser humano y se originó a finales de la década de los 40, la cual comprende agrupar las dimensiones del comportamiento de líder dentro de las que se encuentran, la estructura de iniciación, la consideración, orientación a la tarea y orientación al empleado. El liderazgo orientado a la tarea tiene parecido a la 
estructura de iniciación y el orientado al empleado relación con la consideración.

En este sentido, si se toma como referencia el origen de la teoría de la participación del líder de Vroom y Yetton (1973), que relaciona, el comportamiento del liderazgo y la participación en la toma de decisiones, se observa un modelo normativo que sostiene que el comportamiento del líder debe ajustarse para reflejar la estructura de la tarea, sea esta rutinaria, no rutinaria o en cualquier punto intermedio.

Además, este permite una serie de pasos, normas o reglas para orientar la participación del líder en la toma de decisiones. El modelo consiste en un árbol de decisiones a la luz de siete contingencias propuestas y cinco estilos de liderazgo alternativo, los cuales van desde la toma de decisión unilateral por parte del líder, pasando por la toma de decisiones compartida con el grupo a través del consenso.

Por otro lado, Blake y Mouton (1975), citado por Bittel y Newstron (1993), aportaron la rejilla de liderazgo, también conocida como el "Grid Gerencial", la cual se estudia actualmente en las organizaciones para comprender la forma de pensar de los líderes y su relación con la actuación.

En la rejilla de Blake y Mouton (1975) (Figura 1), en el eje X se identifica la preocupación por la producción del líder $y$, en el eje $Y$ la preocupación por las personas. Se observa en el eje $X$, numeral (1.1) al líder indiferente; no se interesa ni en la tarea ni en la gente. Este estilo conduce a una administración empobrecida donde el líder muestra una débil influencia para permanecer como miembro de grupo y lograr resultados.

En la parte superior izquierda, numeral (1.9) se encuentra el líder con alta orientación a la gente y baja orientación a la tarea o producción. Aquí se aprecia el líder orientado a las relaciones, sociable y en un mínimo orientado al logro de los resultados.

En la esquina inferior derecha, en el numeral (9.1) se visualiza el líder con una alta ocupación en la tarea y producción y nulo interés por la gente, esto modela un es-

Figura 1

Rejilla de Liderazgo de Blake y Mouton (1975)

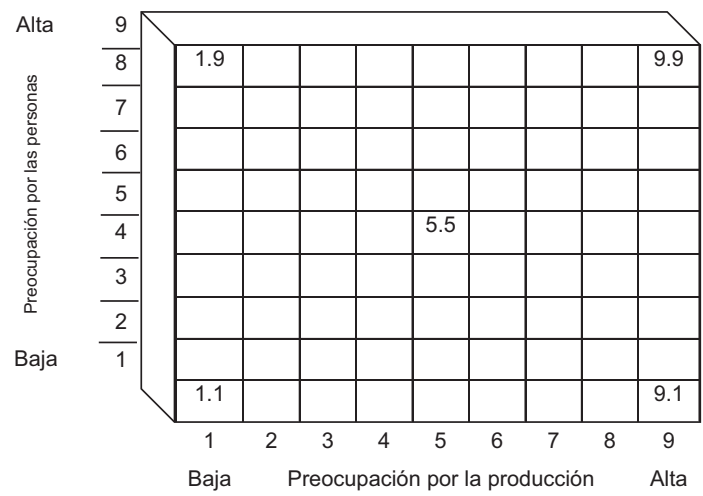

Fuente: Bittel y Newstron (1993:278). 
tilo duro, indiferente a la gente y por tanto orientado solo a resultados. En este espacio el líder considera importante la operación y las personas interactúan poco.

Finalmente, en la esquina superior derecha, numeral (9.9) se encuentra el líder orientado tanto a la tarea como a la gente, lo cual resulta para muchas organizaciones ideal. El líder ubicado en 5.5, mantiene un equilibrio promedio de interés por la gente y por la tarea, es un líder ocupado por ambas dimensiones en forma proporcional y comprometida.

La rejilla del liderazgo Blake y Mouton (1975), evidencia la importancia de equilibrar el interés por el resultado, meta o producción y la gente. No obstante, se cuestiona que en ocasiones los lideres, dependiendo de la situación, deben inclinarse por alguna de dichas dimensiones para lograr los objetivos propuestos.

Por otra parte, Hersey y Blanchard (1974) exponen la teoría situacional; cuya particularidad es la de hacer énfasis en el grupo y en los seguidores del líder. Se sustenta en la decisión del seguidor de aceptar o rechazar al líder en función de la disponibilidad para cumplir la tarea, o de la madurez que demuestra en cuanto a ésta. Se considera la aptitud del seguidor y por ello el rol del líder se orienta a desarrollar justamente esas aptitudes.

A partir de esta teoría se han desarrollado modelos interesantes tales como los cuatro niveles de desarrollo del seguidor, propuesto por Blanchard et al (2007) en su manual de Liderazgo Situacional, el cual ha servido a organizaciones venezolanas para empoderar sus liderazgos, denominando por cuatro siglas: D1, D2, D3 y D4.

En este modelo un seguidor en el nivel D1 está interesado y entusiasmado con la meta pero carece de conocimientos, experiencia y habilidades. Un seguidor en el nivel D2 tiene bajo nivel de competencia y de compromiso. Su actitud proviene de algún grado de frustración o desmotivación quizás por expectativas no satisfechas. En el nivel D3 se encuentran aquellos que tienen un moderado a alto nivel de competencia y un variable nivel de compromiso. Finalmente este modelo indica que un seguidor en nivel D4 tiene un alto nivel de competencia y un alto nivel de compromiso. El seguidor está listo para ocupar otras posiciones, domina totalmente la tarea y está motivado, de allí que, el líder esté llamado a estimular la confianza en su seguidor, y a motivar la creencia en su propia capacidad y competencia.

De modo que, la teoría situacional no deja claro los criterios de selección del líder para escoger a ese grupo interno, pero es evidente que influye en los seguidores y para que estos desarrollen características de personalidad y actitudes parecidas a las de él. Interesante resulta este modelo para la revisión del liderazgo en las organizaciones venezolanas, la objetividad del líder en su gestión y el impacto de este en la satisfacción de los seguidores.

La teoría situacional muestra la importancia de incluir y tomar en cuenta la situación en la cual se desarrolla el proceso de liderazgo, pues ello influye en el estilo que el líder debe adoptar para el logro de los objetivos comunes.

Uno de los modelos de contingencia más reconocidos es el de Fred Fiedler (1967), citado por Robbins (2009), el cual relaciona el estilo de liderazgo y la situación en la cual se encuentra la organización. En cuanto a ésta, Robbins (2009), 
sostiene que se basa en los grupos eficaces los cuales dependen de la armonía entre el estilo de un líder para actuar con sus subordinados y el grado en que la situación le da control e influencia.

Ahora bien, en la actualidad, los retos organizacionales están resultando cada vez más interesantes pero también más complejos, puesto que, temas como tecnología, globalización, redes sociales, revolución ecológica, crisis de valores, entre otros, nos convierte en actores de una sociedad donde se aspira productividad, calidad de vida, calidad emocional y desarrollo integral.

De modo que, las organizaciones continúan siendo espacios para repensar todos estos elementos y el liderazgo una disciplina fundamental para impulsarlos. Resulta significativo en tal sentido, incorporar el enfoque emergente del liderazgo para en un posterior estudio revisar cómo se está desarrollando en Venezuela a la luz de su práctica en las organizaciones.

\section{Liderazgo emergente o contemporáneo}

Un importante valor agregado de los enfoques contemporáneos con relación a las tradicionales teorías, es que consideran el liderazgo capaz de influir en los seguidores a través de la inspiración; esto obedece a la comunicación que el líder sostiene con su grupo. Esto se ha definido como la contextualización que el líder otorga a su estilo, tal como refiere Robbins (2009), la forma de usar el lenguaje para manejar el significado.

Con esta contextualización, los líderes pueden lograr que los seguidores obtengan desplazamientos que hasta ellos mismos ignoraban poder alcanzar y que estos vayan más allá de sus intereses personales.

Tres grandes teorías complementarias han aportado ideas sobre el liderazgo eficaz en organizaciones y grupos. Aunque toman principios de las teorías tradicionales, ofrecen otras interpretaciones para contribuir a comprender el fenómeno del liderazgo, tales como las teorías del liderazgo carismático, el transaccional y el transformacional, así como los enfoques de liderazgo resonante o emocional y el liderazgo coach. Igualmente se valoran hoy estilos donde el líder se fortalece a través del ejercicio de la ética y del espíritu emprendedor como atributos fundamentales.

De acuerdo con Robbins (2009), el impulsor del liderazgo carismático fue Max Weber (1947), quien desde hace más de un siglo definió carisma como "cierta cualidad de la personalidad de un individuo, por virtud de la cual él o ella permanecen aparte de la gente común y son tratados como si tuvieran cualidades supernaturales, súper humanos o al menos con poderes específicos excepcionales". El carisma es una palabra griega que significa regalo, don o cualidad.

Posteriormente Robert House (1988), citado por Robbins (2009), expone que los seguidores valoran las aptitudes heroicas o extraordinarias. Estos líderes tienen cuatro características fundamentales: poseen una clara visión, están dispuestos a correr riesgos personales para alcanzar dicha visión, son empáticos y sensibles a las necesidades de sus seguidores y tienen comportamientos extraordinarios. 
Por otro lado, Lussier y Achua (2005), consideran sinónimos los términos de liderazgo carismático y liderazgo transformacional. En este sentido, el carisma se define como el proceso de influencia en las actitudes y premisas de los integrantes de las organizaciones para realizar cambios importantes y comprometerse con los objetivos organizacionales.

Por otra parte, el liderazgo transaccional y transformacional, se centra en los logros de los líderes, más que en sus características personales y las reacciones de los seguidores. Mientras las organizaciones sigan enfrentando los desafíos globales, mayor será la necesidad de líderes que trabajen y pongan en marcha con acierto estrategias audaces para transformar o alinear a la organización con el nivel de turbulencia ambiental. Es una forma de liderazgo que sirve para cambiar el status quo, es decir, el estado actual de las cosas, pues articula los problemas en el sistema actual y una visión convincente de los que podría ser una nueva organización para los seguidores (Lussier y Achua, 2005).

Bass y Avolio (1994), identifican dos clases fundamentales de liderazgo: "transaccional" y "transformador". Los líderes transaccionales tienden a orientarse a la acción, mientras que los transformadores se inclinan a utilizar un nivel de visión más elevado. Algunas situaciones de liderazgo requieren el desarrollo de habilidades básicamente transaccionales mientras que otras precisan de procesos fundamentalmente transformacionales.

En una comparación entre el liderazgo transformador y el transaccional, Burns (2003), establece que el primero se basa en valores finales tales como justicia, igualdad y derechos humanos, transmitidos a través de la educación, mientras que el segundo se apoya en valores modales como la honestidad, lealtad y respeto por medio del entrenamiento en el cual puede usarse la coerción.

Por su parte, Bass y Avolio (1994), definen a los líderes transformadores primariamente en términos de los efectos del líder sobre sus seguidores, quienes sienten confianza, admiración, fidelidad, respeto hacia el líder y son motivados a hacer más de los que se espera de ellos. En el liderazgo transformador se plantean los siguientes aspectos:

- Carisma (influencia idealizada): proporciona visión y sentido de misión, origina orgullo, genera respeto y confianza. Otorga a sus colaboradores un sentido de propósito. Constituye un modelo que los colaboradores aspiran a imitar.

- Inspiración: comunica altas expectativas, utiliza símbolos para enfocar, expresando los propósitos importantes de manera sencilla.

- Estímulo intelectual: promueve y enfatiza la inteligencia, racionalidad y solución cuidadosa de problemas. Las ideas del líder estimulan a sus colaboradores a reconsiderar sus propias ideas. Los viejos problemas se ven así con nuevos ojos.

- Consideración Individualizada: esta significa la atención personal, el trato a cada empleado de manera individual, capacitándolo y aconsejándolo.

Ahora bien en cuanto al liderazgo resonante, Goleman et al (2005) expresan que aun cuando no cabe duda que el 
pensamiento analítico y la claridad conceptual sean habilidades fundamentales e imprescindibles para ejercer el liderazgo, la capacidad intelectual, por sí sola no hace al líder. Los grandes líderes son personas que saben manejar las emociones. Su éxito no depende tanto de lo que hacen como del modo en que lo hacen.

El líder desempeña un papel fundamental en el clima emocional colectivo ya que explícita o implícitamente determina la norma emocional del grupo. Si un líder carece de la capacidad para encauzar las emociones adecuadamente, nada de lo que haga funcionará como es debido.

Por lo tanto, el Liderazgo resonante, para Goleman et al (2005), es un tipo de liderazgo que sintoniza con los sentimientos de las personas y los encauza en una dirección emocionalmente positiva. Uno de los signos más evidentes del líder resonante es el optimismo y el entusiasmo que exhiben sus colaboradores. La resonancia le da amplitud y permanencia al impacto emocional del liderazgo.

Este tipo de líderes sabe movilizar en los demás el estado de ánimo más adaptado a las circunstancias, utilizando su empatía para sintonizar con el tono emocional de sus subordinados. Cuando el líder no sabe empatizar ni interpretar adecuadamente las emociones ajenas genera disonancia y trasmite innecesariamente mensajes perturbadores. El resultado es que la atención del grupo se desvía de su misión y se centra en el malestar colectivo. Este líder crea grupos discordantes en los que las personas tienen la continua sensación de hallarse desconectados de los demás.
Organizaciones venezolanas están orientando parte de su estrategia a fortalecer el liderazgo emocional y resonante en sus directivos, gerentes y supervisores. Institutos como el Instituto de Estudios Superiores en Administración (IESA, 2007), presenta dentro de su portafolio anual, actividades formativas a través de programas, talleres y dinámicas gerenciales cuyos contenidos desarrollan los conceptos de inteligencia emocional.

Según El Instituto de Gerencia Estratégica del Estado Zulia (IGEZ, 2012), en los siete (7) años comprendidos desde el 2005 y hasta el 2012, seiscientos cuarenta (640) empresas de la región occidente contrataron actividades para fortalecer el liderazgo resonante y coach en sus directivos, gerentes y supervisores y se han formado un total de un mil cincuenta y cuatro (1054) participantes. Este es un indicador de la importancia que está adquiriendo en las organizaciones venezolanas, el estilo de liderazgo contemporáneo sustentado en el ser integral.

En cuanto al Liderazgo Coach, desde 1980 hasta nuestros días el coaching se ha desarrollado ampliamente. O'Connor y Lages (2005), indican que la esencia del coaching es "ayudar a las personas a moverse en pro de desarrollar las habilidades que desea así como de encaminarse hacia la dirección que desea despertando de manera congruente su potencial".

Por su parte, Echeverría (2006), indica que las distinciones, a la hora de formarnos como coach, se traducen en escuchar, hablar y observar. En el campo empresarial, el escuchar efectivo ha lle- 
gado a adquirir la máxima potencialidad y si se desea hacerlo se debe primero observar, no solo los estados verbales y del cuerpo, sino también los emocionales.

El coaching ayuda a desarrollar las competencias necesarias para el profesional tales como: facilitar procesos de transformaciones individuales y grupales que permitan el logro de los objetivos, diseñar y coordinar talleres, cursos y seminarios para posibilitar el desarrollo personal y profesional y realizar consultoría en organizaciones (Echeverría, 2006).

Ahora bien, con base al concepto de coaching, se encuentra en el mismo un nuevo estilo de liderazgo, denominado el liderazgo coaching, donde el líder lleva a sus seguidores hacia el claro entendimiento de la importancia de su trabajo, de la meta compartida y de los valores, para orientar los planes, decisiones y acciones.

Esto es posible cuando el líder ayuda al seguidor a encontrar su propia potencialidad, no le dice cómo hacerlo sino que lo acompaña en la búsqueda de sus mejores herramientas, capacidades y competencias para accionar hacia el logro del objetivo. Este es un estilo de liderazgo en el cual se construye confianza, se acompaña al seguidor empoderándolo para el logro de sus metas logrando su autonomía, responsabilidad y compromiso, basado en el libre albedrío. Es un liderazgo que reconoce el error desde otra perspectiva, como una posibilidad de logro y aprendizaje en sustitución del estilo que genera miedo y limita la potencialidad.

Otro modelo emergente de liderazgo es el auténtico y ético, concepto reciente y con limitadas investigaciones al respecto. Según Robbins (2009), los líderes auténticos saben quiénes son, lo que creen y valo- ran, sus seguidores los consideran personas éticas y una de sus cualidades más importantes es que generan confianza. Esta confianza es una expectativa positiva de que otra persona no actúa de manera oportunista: con palabras, acciones o decisiones. La expectativa positiva implica conocer a la persona o familiarizarse con ella, pues la confianza no se compra, se construye y para eso hace falta la interacción, que se conozca al líder y se éste claro en quien es. La oportunidad significa que se espera no ser aventajado por el otro, no ser decepcionado.

La ética en el liderazgo se ha convertido en un tema que ha penetrado los espacios organizacionales con mucha fuerza. Todo lo relacionado con códigos, principios y normas está apoyando la toma de decisiones en una búsqueda por lo correcto, por lo justo y por lo que se espera en el marco del deber ser. No obstante, se escucha cada vez más cómo las acciones carentes de ética o acciones ilegales están la orden del día en todos los ámbitos de nuestra sociedad.

Según Lussier y Achúa (2005), la ética es el conjunto de normas que rige la conducta en términos de lo que es o no correcto. Al momento de revisar el liderazgo ético, se debe tener en cuenta algunas consideraciones como la influencia de los rasgos, las actitudes, la moral establecida y la situación en la ética, cómo la gente justifica algunas actitudes no éticas y cuáles son las normas básicas para una conducta ética esperada socialmente.

Los rasgos y estilos de personalidad influyen en el comportamiento ético, por ejemplo, las personas responsables tienden a ser más éticas que aquellas que no se responsabilizan por sus actos. Los 
individuos con buen locus de control interno, que asumen las consecuencias son más éticos que aquellos que siempre buscan las causas en los demás y no asumen sus compromisos. Los individuos emocionalmente estables construyen acciones más éticas que aquellos cuya emocionalidad está desequilibrada. Ser ético tiene que ver con la integridad y también con la actitud ante la vida, por lo general las personas con actitudes positivas acerca de la ética tienden a ser más éticos que aquellos que la cuestionan.

Otro factor que incide en el comportamiento ético es el desarrollo moral. Éste se refiere a la diferenciación del bien y el mal, y a escoger el bien (Lussier y Achua, 2005). Siendo otro elemento influyente en la ética la situación que se presenta y determina la actuación, es decir, cuando hay escenarios altamente competitivos y poca supervisión hay más probabilidad de actuar en forma no ética. Igualmente si en la organización no hay valores decretados y modelados o un código de ética que oriente la actuación de los colaboradores, o si no se castiga el comportamiento no ético.

Echeverría (2011) plantea en su estudio Ética y Coaching Ontológico, que la crisis más profunda que hoy la humanidad experimenta, y en especial la cultura occidental dentro de su proceso de globalización, es la crisis en el ámbito de la ética. Expresa la misma a través de tres niveles que son interesantes para cuestionar y debatir: 1) La creciente dificultad para comprender el sentido de la vida, 2) la dificultad para construir y preservar relaciones significativas y 3) la creciente dificultad para consolidar modalidades armoniosas de convivencia dentro de nuestras comunidades.
En una sociedad que presiona por lograr niveles de equidad, se observa cómo se reproduce la desigualdad y la exclusión. En una sociedad que acentúa los valores democráticos, frecuentemente vemos cómo se impone el ejercicio de la violencia, la separación y la discriminación. Se necesita con urgencia avanzar hacia una nueva ética de convivencia que permita rectificar y asegurar la preservación de las organizaciones y del planeta.

El liderazgo ético es una forma de contribuir a la construcción del respeto organizacional como base de las intervenciones para la transformación, el desarrollo y la competitividad.

Por otro lado, en el liderazgo emprendedor, desde finales de la década de los setenta, el concepto del emprendedor se ha pronunciado como necesario, rompiendo con el paradigma del colaborador dependiente que puede ser capaz de iniciar un proyecto, una idea o un negocio en beneficio propio y de la sociedad. El liderazgo emprendedor motiva, impulsa e inspira este proceso ayudando a descubrir posibilidades en sus seguidores a partir de su modelaje.

Zambrano (2010), en su guía práctica Coaching con Acción para Emprendedores e Innovadores, muestra como el modelo de David McClelland (1988), citado por Zambrano (2010), retrata tres conjuntos de comportamientos que los líderes exitosos poseen. En el conjunto del logro, el líder emprendedor se caracteriza por buscar oportunidades, por su acción persistente, cumplimiento y compromiso, búsqueda y exigencia de niveles de calidad y eficiencia y actitud para asumir riesgos controlados, en el conjunto de la planificación es un individuo que fija metas, 
busca información y planifica sistemáticamente y en el conjunto del poder se maneja con persuasión y redes de apoyo y posee autoconfianza, así que, promueve la iniciativa, la proactividad y la creatividad, aspectos fundamentales hoy en el mundo organizacional.

Por tanto, los tres tipos de liderazgo, carismático, transaccional y transformacional conforman un paradigma moderno para la comprensión del proceso de liderar y muestran especial énfasis en el análisis de la relación del líder con sus seguidores. Las modernas tendencias apuntan al rescate de las condiciones y rasgos del liderazgo que puede encontrarse en todas las personas y en su aprovechamiento para el desarrollo personal y profesional del equipo y de la organización.

De modo que, son tendencias que despiertan la necesidad del líder de reconocer la importancia de la formación y el desarrollo de capacidades y competencias de sus seguidores. El liderazgo resonante por su parte, conduce al líder a reconocer a un seguidor dotado de emociones, capaz de relacionarse, de empatizar, de sentir y a entender el impacto de dicha emoción en las decisiones, llevando a humanizar el proceso de liderazgo. Los estilos de liderazgo que se promueven actualmente, son sustentados en aspectos relacionados con la autoestima, autoconfianza y valores, generadores de las mejores cualidades de los equipos. Un estilo renovado que se fomenta en pro de las nuevas generaciones.

Por otro lado, la investigación desarrollada por Petit y Gutiérrez (2007) para describir el modelo de liderazgo con empowerment e identificar su perfil pro- motor de la innovación en las organizaciones empresariales, logra un punto de encuentro entre la teoría de la innovación, el enfoque de gestión del conocimiento y la teoría gerencial, el cual consiste en que todas estas perspectivas teóricas asumen el liderazgo como determinante de la innovación.

Con relación al liderazgo innovador pues la teoría de la innovación no considera al seguidor emprendedor como parte determinante del proceso innovador, sino solo a los empresarios emprendedores, a quienes considera dotados de visión privilegiada, intuición y determinación para innovar. Las teorías de enfoque de gestión de conocimiento y la teoría gerencial, explican cómo es posible aprovechar las ideas explotando recursos, generando capacidades y desarrollando competencias en la organización a partir del aporte de todos sus miembros, lo cual constituye el eslabón para relacionar las variables liderazgo empowerment e innovación.

De igual forma, Torre (2012) en su análisis del liderazgo situacional como herramienta fundamental de productividad en las organizaciones empresariales, reporta que los gerentes de las empresas objeto de estudio tienen características de liderazgo situacional, siendo las menos utilizadas en su gestión la empatía y la adaptabilidad. Ponen en práctica la colaboración y el trabajo en equipo. Aunque poseen características de líderes visionarios no usan las características para lograr productividad pues carecen de empatía, lo cual no les permite establecer una filosofía de gestión en consonancia con el talento humano a su cargo. 
Por su parte, Murati y Pozo (2013), al abordar el desarrollo de un modelo de liderazgo para las empresas Siderúrgicas de Guayana, analizan las características de diferentes modelos de liderazgo y desarrollan un modelo fundamentado en la eficacia gerencial y el humanismo, sustentado en valores y principios éticos, todo combinado con la necesidad de desarrollar conocimientos y habilidades. Las empresas de éste sector empresarial invierten gran cantidad de recursos en formar a los líderes que requieren, no obstante, aún se revelan estilos autocráticos con dominio de procesos técnicos y limitada sensibilidad humana.

El modelo que proponen los autores se basa en principios de eficacia, gerencia y humanismo con énfasis en valores tales como honestidad, participación, inclusión, creatividad, disciplina, compromiso, responsabilidad social entre otros. Este modelo realza la dimensión humana y contribuye a desplazar el paradigma de gestión basado en objetivos meramente económicos hacia un liderazgo que considera el capital humano como integral y cohesionado en el sistema familia, comunidad y país. Esto implica líderes que direccionen y conduzcan a sus colaboradores no solo a lograr los objetivos individuales y organizacionales, sino en todo el sistema social.

\section{Algunas reflexiones sobre el Liderazgo en Organizaciones Venezolanas}

A la luz de las teorías emergentes o contemporáneas, se encuentra el interés en indagar cómo se está desarrollando el liderazgo en las organizaciones venezo- lanas. En este sentido, se analiza el liderazgo en sectores importantes de Venezuela: educativo, pequeña y mediana industria y empresarial.

En el sector educativo, Camacho (1997) realiza aportes de atributos del liderazgo transformacional en comparación con atributos de docentes de educación básica en el Estado Mérida. El autor precisa entre los atributos más valorados en un líder educativo: la honestidad y la inteligencia, coincidiendo con Kaufmann (1997), quien resalta entre las cualidades de un líder, la honestidad como el rasgo más valorado.

Pérez (2011), al indagar sobre las competencias del liderazgo transformacional en el quehacer gerencial de los directores de las Instituciones Básicas del Estado Trujillo, se encuentra con la ausencia de competencias de influencia e impacto, líderes poco estimuladores, interesados escasamente en el conocimiento y con limitada visión de la organización como un todo. A su vez, no se establecen redes, dificultando con esto sus esfuerzos para impulsar cambios.

Al analizar la problemática del docente para llevar a cabo su práctica, aun con los recursos adecuados, por una falta de liderazgo, Mantilla (2012) encontró que este profesional de la educación básica no posee liderazgo transformacional, resultando las categorías valores y tipos de liderazgo los aspectos menos evidenciados; siguiendo las prácticas pedagógicas esquemas tradicionales con poca innovación.

También, González (2008) expresa que los docentes universitarios del Estado Zulia presentan un liderazgo predominante en la institución para la cual labo- 
ran; son carismáticos, estimulan al personal a su cargo, son personas honestas y manejan una buena comunicación con sus alumnos y compañeros de trabajo, y proyectan un liderazgo eficaz.

Los resultados generales arrojados para este sector, indican la necesidad de fortalecer el liderazgo transformacional en las unidades educativas de educación básica, pues se evidencia ausencia del mismo o limitado ejercicio de sus características principales. Este estilo de liderazgo promueve la transformación y los cambios, por lo que se hace conveniente incorporarlo al sector educativo en pro de la evolución de los procesos de formación del talento humano. A nivel de docencia universitaria el liderazgo se revela más fortalecido con un estilo eficaz.

En la pequeña y mediana industria (Pyme), Salazar (2008) al indagar sobre la relación entre el coaching y el liderazgo visionario en los Gerentes de este tipo de empresas en el Municipio Maracaibo, Estado Zulia, explica que los gerentes representan en su mayoría cualidades de coach, a excepción de la flexibilidad. Tienen estrategias de acción rígidas, no ejecutan roles ni de entrenadores ni de consejeros, no brindan apoyo para el aprendizaje ni el desarrollo, siendo solo correctivos.

Los gerentes de la Pyme poseen características de líderes visionarios a excepción de la asertividad, establecen relaciones emocionales y utilizan una comunicación efectiva. No obstante, no comunican adecuadamente la visión y la misión de la empresa requiriendo fortalecer esa competencia.

Al correlacionar la variable coaching y liderazgo visionario se encuentra una correlación positiva lo cual refleja que, en tanto los líderes utilicen técnicas de coaching actuarán como visionarios.

Por otro lado, Gascón (2012), al realizar una investigación cualitativa con sujetos líderes y gerentes de Pymes, los resultados se inclinaron por matices de liderazgo carismático, con rasgos autoritarios y presencia de patrones de comunicación orientados más a la tarea que a la gente.

En gerentes líderes más renovados, pertenecientes a generaciones más jóvenes y con estudios superiores, surgen estilos de liderazgo resonante y relacional con indicios de transformacional. Rasgos de liderazgo transaccional y situacional, donde inciden el tipo y origen de las Pymes, los apoyos, obstáculos y retos que se presentan.

En éste orden de ideas, La Secretaría Permanente del Sistema Económico Latinoamericano y del Caribe (SELA, 2010), en un estudio denominado Visión Prospectiva de las Pymes sostiene el carácter esencial del liderazgo como una combinación de personalidad y visión, en donde plantea el necesario desplazamiento de un líder motivador en pro de una meta bajo el indicador controlador, hacia un líder orientado a desarrollar nuevas habilidades y ser facilitador del cambio en las Pymes.

El estudio planteó la necesidad de un estilo de liderazgo contagioso, el cual se corresponde con el liderazgo resonante, basado en las personas, en equipos, redes y estructuras diferentes. Un liderazgo con consideración en la visión y con el coraje para remover las estructuras existentes, con base en una comunicación que propicie la integración, además de considerar a los empleados como lo más importante en la organización 
cuyo talento es el capital humano (Goleman et al, 2005).

Por tanto, se evidencia el liderazgo autocrático con tendencia a acciones rígidas que prevalece en los resultados obtenidos en las Pymes, así como una orientación predominante hacia la tarea por encima de la orientación a la gente. Limitaciones para comunicar la visión y plantear estrategias a futuro. Igualmente son indicadores del liderazgo presente, no obstante se comienza a revelar un estilo relacional, interesado en sostener comunicación y ser promotor de cambio, lo cual indica un desplazamiento en las nuevas generaciones hacia el aspecto humano. Esto parte de las tendencias mundiales en el liderazgo emergente.

De allí que, al revisar los hallazgos, se aprecia en el sector empresarial la necesidad de un desplazamiento hacia un estilo de liderazgo más humano, con mayor énfasis en la gente. Se evidencia un estilo de liderazgo situacional, con características de líderes visionarios, no obstante hay carencia de una comunicación empática, lo cual dificulta emprender acciones en conjunto con el equipo para alcanzar la visión propuesta. Esto se corresponde con la necesidad de continuar explorando y proponiendo modelos con tendencias emergentes que promuevan el interés en el talento humano, así como los valores de comunicación, trabajo en equipo e integración.

En cuanto a algunas tendencias en el liderazgo en el país, Zamora y Poriet (2006), explican que como hallazgo fundamental que las organizaciones continuarán ejerciendo sus principios gerenciales pero cada vez más orientadas a lograr una transición de gestor a líder para lo que requieren seres integrales, emprendedores, gestores y líderes.

Por su parte, Sampedro y Arana (2009), al describir al gerente venezolano desde una perspectiva de liderazgo, se insertan en la competencia global organizacional a partir de sus fortalezas y no sólo enfocando sus brechas o debilidades.

Esto resulta importante si se entiende que los gerentes de recursos humanos son los responsables de administrar los planes de desarrollo del talento humano y el fortalecimiento de sus competencias. Los autores encuentran también como hallazgo que el gerente venezolano poseen muchas de las características requeridas para asumir los retos actuales, pues se revela como privilegiado por su inventiva y capacidad de adaptación en la era de la innovación.

En este sentido, Marquez y Avellán (2008), citado por Sampedro y Arana (2009), encuentran en un estudio efectuado en el Instituto de Estudios Superiores de Administración (IESA), que los gerentes líderes venezolanos logran acuerdos y son buenos negociadores, ceden en algunos puntos de vista si lo consideran necesario para lograr sus objetivos, utilizan el análisis y la lógica como forma dominante de lograr objetivos, abren espacios para la participación y brindan reconocimiento, no obstante son poco sensibles a las necesidades de los otros.

Finalmente, Ángel (2004), en su perspectiva de obtener las implicaciones de la complejidad para la conducción política y gerencial del país, como un reto del liderazgo en Venezuela plantea la necesidad de un liderazgo más inclusivo, que se profundice en programas para el 
desarrollo de liderazgo donde se cree dirección, alineamiento y compromiso, propone convertir el cumplimiento de las tareas de liderazgo en el corazón del liderazgo, lograr participación y cooperación incrementando las capacidades de la gente y logrando que la gente se involucre en los cambios que hacen falta.

El autor agrega se requiere en Venezuela de un liderazgo conectivo, que el líder venezolano tenga capacidad para crear sentido compartido, enfoque múltiple, experimente conflictos encontrados desde diferentes perspectivas. Por otra parte propone que este liderazgo cree conexiones, redes, y diversifique la forma de relacionamiento.

Sintetizando, los retos del siglo XXI, a la luz de las investigaciones consultadas, reafirman la necesidad de continuar desarrollando competencias en los líderes, fundamentadas en los modelos emergentes. Se requiere pasar de un mero gestor a líder con cualidades de emprendedor y valores de integridad. La inventiva, la capacidad de adaptación y lograr acuerdos son características esenciales para el logro de los objetivos, en especial dentro de un contexto que se visualiza en escenarios de incertidumbre, por lo que el líder venezolano se visualiza como un privilegiado en creatividad y potencialidad de innovación así como emprendedor.

La ausencia de un liderazgo orientado a la gente invita a considerar a futuro el desarrollo de competencias humanas, donde la sensibilidad, la empatía y los valores de inclusión, cooperación y participación movilicen la gestión. Ese reto está planteado para la gerencia de talento humano, dónde el desafío mayor se encuentra en el desarrollo de líderes con en- foque múltiple, con habilidades para construir redes y con competencias para manejar los cambios a través de sólidos vínculos con el talento humano.

\section{Conclusiones}

El concepto de líder y liderazgo ha evolucionado en función de las expectativas del mundo cambiante, donde los seres humanos se desplazan en la búsqueda de mejores prácticas y estados de bienestar. Es así como en el Siglo XXI, el resurgimiento del Ser Humano como protagonista del cambio es la bandera para repensar el liderazgo. Aspectos tales como los valores, la calidad del servicio, el aprendizaje e innovación continua, la visión de comunidad, sociedad y mundo se hace imperante en el desempeño del líder.

Estilos de liderazgo carismático, transaccional y transformacional se revelan como posibilidades para lograr esa influencia inspiradora que motiva a los seguidores al logro de los objetivos propuestos. El liderazgo carismático y el transformacional están sustentados en características del líder y tienen la particularidad de lograr efectos emocionales, crear ambientes de cambio y articular visiones claras. No obstante en el caso del carismático las investigaciones revelan que es un tipo de liderazgo más individualizado y que no siempre logra los cambios en las organizaciones.

El liderazgo transformacional se centra más en los logros que los líderes pueden alcanzar y se fundamenta en el logro justamente de la visión. Se fundamenta en valores finales de justicia, igualdad y derechos humanos. Es por ello que puede ser visto como un proceso de in- 
fluencia en individuos y hasta en sistemas sociales de gran magnitud.

Como modelos de liderazgo más recientes y novedosos dentro de los sistemas organizacionales se encuentran el liderazgo resonante, el coach, el emprendedor y estilos denominados ético y auténtico que revelan la necesidad de incorporar estas cualidades fundamentales en el rol del liderazgo. Modelos que presentan la característica común de incluir al Hombre como Ser Integral y de trabajar el elemento confianza en la interacción. Para ello estos modelos promueven la consideración de un componente emocional en las interacciones, invitan a la revisión de valores éticos tales como el respeto y la integridad, promueven el aprendizaje como elemento de transformación y generación de cambios e impulsan el espíritu emprendedor para generar productividad y calidad de vida a partir del desarrollo de potencialidades.

Al analizar algunas de las investigaciones del Liderazgo en Organizaciones Venezolanas, se aprecia que hay rasgos muy valorados en el liderazgo tales como la honestidad y la inteligencia. Los líderes poseen oportunidades de continuar fortaleciéndose pues hay carencia de competencias para influir e impactar, así como algún grado de desmotivación y limitada visión para ver el todo dentro del sistema. El liderazgo transformacional no se evidencia, no obstante existen líderes que sí estimulan, que poseen una buena comunicación y que proyectan liderazgo eficaz. En el sector de Pymes, los niveles gerenciales tienen características de rigidez y son más correctivos que entrenadores y asesores, presentando grados de comunica- ción adecuada y con oportunidades de mejora en la forma de comunicar la visión a sus seguidores.

Las tendencias indican que Venezuela requiere líderes más fortalecidos y orientados a la competitividad, con visión transformadora y promotores de confianza, de participación, de conocimiento y de actitud favorable, traducida en optimismo. Líderes que innoven y otorguen empowerment a su gente, que dentro de sus estrategias sean más empáticos y flexibles, resultando el líder venezolano como un privilegiado en creatividad y potencialidad de innovación así como emprendedor.

Otra de las tendencias sugeridas en las investigaciones es el desarrollo del liderazgo conectivo, un liderazgo impulsor y creador de redes desde todas las dimensiones para el logro de los resultados, orientado a diversificar la forma de relacionamiento, donde una vez más se aprecia la importancia de las interacciones, con una orientación profunda a construir vínculos laborales entre líder y seguidor.

\section{Referencias bibliográficas}

Ángel, Alfredo (2004). Los Retos del Liderazgo en Venezuela: Implicaciones de la Complejidad para la Conducción Política y Gerencial del País. Aca Consultores. Venezuela.

Bass, Bernard y Avolio, Bruce (1994). Mejorar la Eficacia Organizacional Liderazgo Transformacional. Sage Publications, Inc. EE.UU.

Bennis Warren y Nanus Burt (1985). Líderes. Las cuatro claves del liderazgo eficaz. Editorial Norma.

Bittel, Lester y Newstron, John (1993). Lo que todo Supervisor debe saber. Editorial McGraw-Hill. México. 
Blanchard, Ken; Zigarmi, Patricia y Zigarmi, Drea (2007). Liderazgo Situacional. Manual del Participante. Las Compañías Ken Blanchard. EE.UU.

Burns James Mc Gregor (2003). Transforming Leadership. Grove Press, New York.

Camacho, Carlos (1997). Rasgos Frecuentes del Liderazgo Transformador en Docentes de la Unidad Educativa Señor de la Buena Esperanza, Dependientes de las Granjas Infantiles de Mérida. Universidad de los Andes. Facultad de Humanidades y Educación. Mérida Venezuela.

De Pree, Max (1993). El auténtico liderazgo, los atributos esenciales de un gran líder. Javier Vergara Editor, S.A. Buenos Aires.

Echeverría, Rafael (2006). Ontología del Lenguaje. J C Sáez Editor. México.

Echevería, Rafael (2011). Ética y Coaching Ontológico. JC Saez Editor. Chile.

Gascón, Manuel (2012). Aproximación Teórica a la Ontología del Liderazgo Gerencial en las Pymes Estado Lara. Revista arbitrada Honoris Causa de la Universidad Ycambú. Vol 3. Número 2. Diciembre 2012. Venezuela.

Goleman, Daniel; Boyatsys, Richard y McKee, Annie (2005). Líder Resonante Crea Más. Editorial Random House. México.

González, Odris (2008). Liderazgo Transformacional en el Docente Universitario.

Revista Multiciencias. Enero-Abril año/Vol. 8 número 001 ISSN 13172255. Universidad del Zulia. Punto Fijo. Venezuela.

Instituto de Estudios Superiores de Administración IESA (2007). Manual de apoyo. Diplomado de Coaching Gerencial. Caracas. Venezuela.

Instituto de Gerencia Estratégica del Estado Zulia IGEZ (2012). Estadísticas de participación en actividades aca- démicas. Área Liderazgo y Coaching Organizacional.

Kaufmann, Alice (1997). Liderazgo Transformador y Formación Continua. Revista Española de Investigación Sociológica, pp 63-183.

Lussier, Robert y Achua, Cristopher (2005). Liderazgo. Teoría, Aplicación y Desarrollo de Habilidades. Editorial Thomson Learning. México.

Mantilla, Pedro (2012). Liderazgo Transformacional sustentado en Valores para la Práctica Pedagógica de los Docentes de Educación Básica desde un Enfoque Constructivista. Publicado por Doctorado y Maestría UNIEDPA. Investigación en Educación y Salud.

Murati Ruiz, F. y Pozo Rodríguez, J. (2013). Hacia un nuevo modelo para el ejercicio del liderazgo en las empresas siderúrgicas. Revista Observatorio de la Economía Latinoamericana. $\mathrm{N}^{\circ}$ 178, Noviembre 2013. Texto completo en http://www.eumed.net/cursecon/ecolat/ve/2013/empresas-siderurgicas-venezuela.html. Consulta: Diciembre 2013.

O'Connor, Joseph y Lages, Andrea (2005). Manual para Certificación Internacional de Coaching. Red Internacional de Consultoría. Brasil.

Pérez Florinda (2011). Competencias de Liderazgo Transformacional Subyacente en los directores de las Instituciones de Educación Básica de la Parroquia Escuque. Revista arbitrada del Centro de Investigaciones y Estudios Gerenciales A. C. Barquisimeto, Venezuela. Año 2 Número 4 (pp 1-19).

Petit, Elsa y Gutiérrez, Lorena (2007). Liderazgo con Empowerment: Promotor de la Innovación. Revista Venezolana de Gerencia, Vol. 12, núm. 38, abril-junio, 2007 Universidad del Zulia. Venezuela. pp. 207-212. 
Robbins, Stephen (2009). Comportamiento Organizacional. Editorial Pearson. Prentice Hill. México.

Salazar, Josefa y Portillo de Condiré, Isabel (2008). Coaching y Liderazgo Visionario. Forum Humanes. Revista Electrónica de Investigación. Volumen 1 Número 1-2008. Universidad Dr. Rafael Belloso Chacín. Venezuela. http://publicaciones.urbe.edu/index.php/forumhumanes/issue/view/ 98/showToc.Consulta10-01-2014.

Sampedro, Jesús y Arana, Arnoldo (2009). El Gerente Venezolano en Perspectiva. Investigación publicada en la Edición Gerencia en tiempos de Cambio. Revista Portafolio de Inversiones, Año 5, No. 18, Venezuela, pp. 1-6.
Sistema Económico Latinoamericano y del Caribe SELA (2010). Visión Prospectiva de las Pymes. Respuestas ante un Mundo Complejo y Competitivo. Mayo 2010. SP/DI Número 4-10.

Torre, Roque (2012). Liderazgo Situacional como Herramienta fundamental de Productividad en las Organizaciones Empresariales. CYSLATO, C.A. Venezuela.

Zambrano, Mauricio (2010). Guía Práctica. Coaching con acción para Emprendedores e Innovadores. Editorial Editoriales Varias Caracas, Venezuela.

Zamora, Ángel y Poriet, Yenitza (2006). Papel de los Líderes y Nuevas Tendencias de Liderazgo en el Siglo XXI. Revista FCES. Volumen XVII, No.1, Escuela de Relaciones Industriales, Universidad de Carabobo. Venezuela, pp 61-73. 